\title{
The changing shape of health psychology: a matter of progress or a sign of Thatcher's children coming of age? Commentary on Murray (2012)
}

\section{Jane Ogden, University of Surrey}

Michael Murray (2012) provides a detailed analysis of the changing shape of health psychology over the past 40 years and suggests that there has been a shift from a more traditional challenge to the biomedical model to a recent emphasis on critical reflection and the role of the social and political context. As a writer of one of the textbooks used for his analysis, I found myself questioning the forces that have driven me to write such a publication (Ogden, 2012). And after critical reflection and a consideration of my social and political context have decided that rather than being a matter of progression this shift in perspective can be seen as reflecting a number of tensions relating to the intellectual goals of a textbook, the constituency of a textbook and the identity of the author and the ways in which these have been managed over time.

\section{So why the initial challenge to biomedicine as the focus?}

A matter of goals

As we tell our students, higher-quality work must get beyond the level of description. Yet writing a textbook involves an inherent tension between describing a discipline versus developing and extending it. As academics we want to break new ground and develop new perspectives but a textbook can only reflect and say it as it is, not how it should be. It is a mapping tool for those new to the discipline which synthesises the vast literature so that others no longer need to do so. And although it can be innovative in the story it tells and the map it chooses to offer it is not the forum for novel approaches.

In the early days of the discipline, the goals of the textbooks were therefore to map out the contents of health psychology, define its nature and crystallise what it was and what is was not. In the 1930s, Durkheim defined sociology as not psychology saying:

In a word there is between psychology and sociology the same break in continuity as between biology and physicochemical sciences. Consequently, every time that a social phenomenon is directly explained by a psychological phenomenon, we may be sure that the explanation is false. (1938, p. 104)

Simultaneously, Freud was also dismissing sociology stating that 'sociology too, dealing as it does with the behaviour of people in society, cannot be anything but applied psychology. Strictly speaking there are only two sciences: psychology, pure and applied and natural science' (1933, p. 216). Likewise in the 1970s and 1980s, the aim of health psychology was being defined as to 'investigate and deal effectively with the role of the individual's behaviour and lifestyle in health and dysfunction' (Matarazzo, 1982) which differentiated it from any of its closest neighbours whether it be medical sociology, public health medicine, general practice or even just a 
specialist area of social or biological psychology (Ogden, 2002). It challenged biomedicine to establish its limits and in essence this gave the discipline its boundaries.

\section{A matter of constituency}

Health psychology also has a tension between its two disparate constituencies, namely psychologists and those who work in medicine. Accordingly, many of us not only teach students studying for undergraduate or postgraduate degrees in psychology but also nutritionists, dieticians, physiotherapists, medical students and doctors. Furthermore, we are often the psychologist on a medically funded research grant or have medics on our psychologically orientated projects. Our task is therefore to present psychological theory and research in a way that is sophisticated and detailed enough to satisfy the more puritanical psychologists but is also of relevance and accessible to those working in applied settings. This tension can result in being criticised by psychologists for 'dumbing down' our discipline and being too simplistic if we overly appeal to the practitioners; we have 'gone native' we are told, if we have forgotten our roots. Or the practitioners tell us that it is all 'psychobabble' if we sell them highfaluting theory which is deemed irrelevant and pointless to their real world settings.

In the early days of health psychology, the discipline needed to capture both these constituencies in order to establish itself as credible in both camps. Accordingly, textbooks of the 1970s and 1980s professed to challenge biomedicine to appeal to psychologists whilst prefacing their chapters with anatomical diagrams and medical data to appease the medics; the 'rhetoric and reality' of our discipline (Ogden, 1997). Furthermore, they incorporated psychological theories to illustrate their allegiance to their psychological roots but selected those that were simple, positivist and empirically based that spoke to doctors. Box and arrow models such as the 'Theory of Reasoned Action', 'Health Belief Model' or the 'Transactional model of Stress' made sense to the medical world who needed to make a difference to patient care; we could have selected the theories of Freud, Bowlby, Mead or Husserl which would have sent our discipline in a very different direction. The tension between constituencies was managed and credibility was established.

\section{A matter of identity}

Authors also have their own tensions. As with many textbook authors, I wrote my first edition when I was still a new and junior member of the discipline. I was told by a publisher at a conference in 1994 that writing a textbook would set me up for life (and she was right!) and so embarked upon developing my professional reputation and furthering my career. I teach both health psychology and critical psychology and so have always had a tension between being within and without the discipline and between the professional and more personal perspectives I hold. Yet, I compartmentalised these aspects of myself and wrote my early book(s) to gain respect and recognition. Those early books by others and myself therefore reflected the professional development of academics finding a voice and developing the authority necessary to have that voice. And the challenge to biomedicine helped to establish that authority as if we were against biomedicine we must be for psychology.

In the early days, textbooks, therefore, negotiated the tensions of conflicting intellectual goals, constituencies and personal and professional identities and through challenging biomedicine they gave the discipline its boundaries, credibility 
and generated authority for those that wrote them.

\section{So why has there been a shift to a focus on the sociopolitical context and critical self-reflection over the past few years?}

A new discipline, like a child, needs to please in order to feel pleased. But now, decades later, health psychology, as a securely attached teenager, can start to quietly aggravate, agitate and broaden its horizons. And so what we have seen in the new generation of textbooks is a call to broaden, test and cross the limits of its domain; perhaps we should draw upon sociology? Or philosophy? Or anthropology? And perhaps we should liaise with politicians or even the media? With chapters on health inequalities, policy and the political agenda this confident discipline can shift its goals and make those boundaries, so well established in the early years, become permeable as we call to recognise the non-psychological factors central to an understanding of health.

This now credible discipline need also no longer appease its two constituencies but can challenge its audience with 'Being critical' and 'Some problems with ...' headings. It may even at times rename itself as 'Critical Health Psychology' placing the traditional discipline as inherently uncritical. These criticisms may still be located in isolated boxes and chapters, but the discipline can now not only address the limits of medicine but can turn that critical eye inwards to address its own theories, methods and even the very epistemological position upon which it is based.

And so what of the author(s)? Why are they now taking on the newly critical stance? A junior academic may want to speak out, challenge or criticise but without authority and reputation, as I was once told, 'it's like shouting "rubbish" from the back row' and senior figures get cross and sometimes even lean across the conference table saying 'I know who you are' in a somewhat menacing way! But time and promotion are wonderful things building a sense of daring and even immunity enabling us to give voice to our more critical selves. We have built our sense of authority by mapping the discipline and appeasing our different constituencies so now we can use this authority to shout rubbish from the front row and answer 'and who are you?' even when we really know.

But is it just time and experience that has caused this shift? Murray argues that the more critical voices are not only happening now but mostly coming from Europe (particularly the UK) rather than the USA. I am a 'Thatcher's child', and whilst Reagan was building his 'Star Wars' in the USA and Gorbachev strove for his 'perestroika' in the USSR, people of my generation in Britain were exposed to a rare politicising culture with a figure to hate (Prime Minister Thatcher) and a threatened system (society) to love and fight for. But as we marched and demonstrated for 'socialism' we were also imperceptibly immersed with Thatcher's individualism bringing with it self-determination and independence. This is a strange old mixture! And now we are coming of age. And as we rise through the ranks of our careers thanks to that individualism, self-determination and independence, with many of us being psychologists (again thanks to that individualism, self-determination and independence) we bemoan the loss of society. And so when we write for our inherently individualistic discipline, our politicising culture cannot help but make us criticise this perspective and call for attention to be paid to all the things we marched and demonstrated for in our youths.

Murray (2012) describes a shift in health psychology using textbooks as his data. 
For me, this reflects how a teenage discipline comes of age and can start to challenge the boundaries and credibility it has established in its childhood. For this discipline, at this time, and for writers like myself in particular, it also reflects Thatcher's children coming of age who at last can voice the tensions between the individual and the social that have made us into who we are.

\section{References}

Durkheim, E. (1938). The rules of sociological method. New York, NY: The Free Press. Freud, S. (1933). New introductory lectures on psychoanalysis. (W. J. H. Sprott, Trans.). New York, NY: Norton.

Matarazzo, J. D. (1982). Behavioural health's challenge to academic, scientific and professional psychology. American Psychologist, 37, 1-14. doi:10.1037/0003-066X.37.1.1

Murray, M. (2012). Social history of health psychology: Context and textbooks. Health Psychology Review. doi:10.1080/17437199.2012.701058

Ogden, J. (1997). The rhetoric and reality of psychosocial theories: A challenge to biomedicine? Journal of Health Psychology, 2, 21-29. doi:10.1177/135910539700200103

Ogden, J. (2002). Health and the construction of the individual. London: Routledge.

Ogden, J. (2012). Health psychology: A textbook (5th ed). Buckingham: McGraw-Hill/Open University Press. 